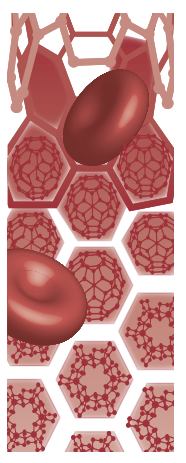

\title{
Enabling cytoplasmic delivery and organelle targeting by surface modification of nanocarriers
}

\begin{abstract}
Nanocarriers are designed to specifically accumulate in diseased tissues. In this context, targeting of intracellular compartments was shown to enhance the efficacy of many drugs and to offer new and more effective therapeutic approaches. This is especially true for therapies based on biologicals that must be encapsulated to favor cell internalization, and to avoid intracellular endosomal sequestration and degradation of the payload. In this review, we discuss specific surface modifications designed to achieve cell cytoplasm delivery and to improve targeting of major organelles; we also discuss the therapeutic applications of these approaches. Last, we describe some integrated strategies designed to sequentially overcome the biological barriers that separate the site of administration from the cell cytoplasm, which is the drug's site of action.
\end{abstract}

Keywords: biological barriers $\bullet$ cell surface modifications $\bullet$ intracellular targeting

- nanocarriers $\bullet$ nanomedicine

Nanocarriers have recently emerged as versatile tools with which to increase the half-life, bioavailability, targeting and safety of various classes of therapeutics [1-5]. An important advance in the field of nanomedicine was the development of nanocarriers able to respond to the physical and chemical stimuli of the biological environment so as to maximize the efficacy of the loaded therapeutics and drive their delivery in function of the surrounding milieu [6-8]. To be effective, carriers must overcome several biological barriers that are encountered during transit from the site of administration to the final target [5]. Clearance action by the major filtering organs (lung, liver, spleen and kidney), and the physical (vascular wall and extracellular matrix), cellular (circulating and resident tissue phagocytic cells) and enzymatic (serum and intracellular digestive enzymes) barriers that characterize the structure of our tissues, have evolved to control the diffusion of exogenous materials within our body. These very efficient biological barriers are the greatest obstacle to the clinical translation of many promising platforms designed for targeted therapy [9].

Depending on their size, shape and surface chemistry, nanoparticles are internalized by the target cells through different pathways (Figure 1) $[10,11]$. After internalization, nanocarriers and their payload are usually sequestered in endosomal vesicles (caveolin-driven endocytosis pathway excluded) [5,12]. Endosomal sequestration of nanotherapeutics is characterized by multiple membrane fusions in which the endocytic vesicles merge sequentially with early and late endosomes until they are compartmentalized in endolysosomal vesicles [13]. Each step is characterized by a progressive decrease of intravesicular $\mathrm{pH}$ and an increase of digestive enzymatic content (lipase, proteases and nucleases) [13,14] that affect the efficacy of the payload, in particular if it consists of such biological therapeutics as peptides, proteins and genetic material (Figure 2). For example, short interfering RNA (siRNA) technology has been extensively investigated in recent decades given its enormous therapeutic potential even at very low concentrations [5].
Alessandro Parodi ${ }^{1,2}$, Claudia Corbo $^{2}$, Armando Cevenini ${ }^{3,4}$, Roberto Molinaro ${ }^{1,5}$, Roberto Palomba², Laura Pandolfi ${ }^{1,6}$, Marco Agostini ${ }^{5}$, Francesco Salvatore ${ }^{2,4}$ \& Ennio Tasciotti*,1

'Department of Nanomedicine, Houston Methodist Research Institute, 6670 Bertner Ave., Houston,

TX 77030, USA

${ }^{2}$ Fondazione IRCCS SDN, Via Gianturco 113, 80143 Naples, Italy ${ }^{3}$ Department of Molecular Medicine \& Medical Biotechnology, University of Naples "Federico II", Via Sergio Pansini 5, Naples 80131, Italy

${ }^{4}$ CEINGE, Biotecnologie Avanzate s.c.a.r.l., Via G. Salvatore 486, 80145 Naples, Italy ${ }^{5}$ Clinica Chirurgica I, Dipartimento di Scienze Chirurgiche Oncologiche e Gastroeterologiche, Università di Padova, Via Giustiniani 2, 35128 Padova, Italy ${ }^{6}$ College of Materials Science \& Optoelectronic Technology, University of Chinese Academy of Science, 19A Yuquanlu, Beijing, China *Author of correspondence Tel: +1 7134417319 etasciotti@houstonmethodist.org 


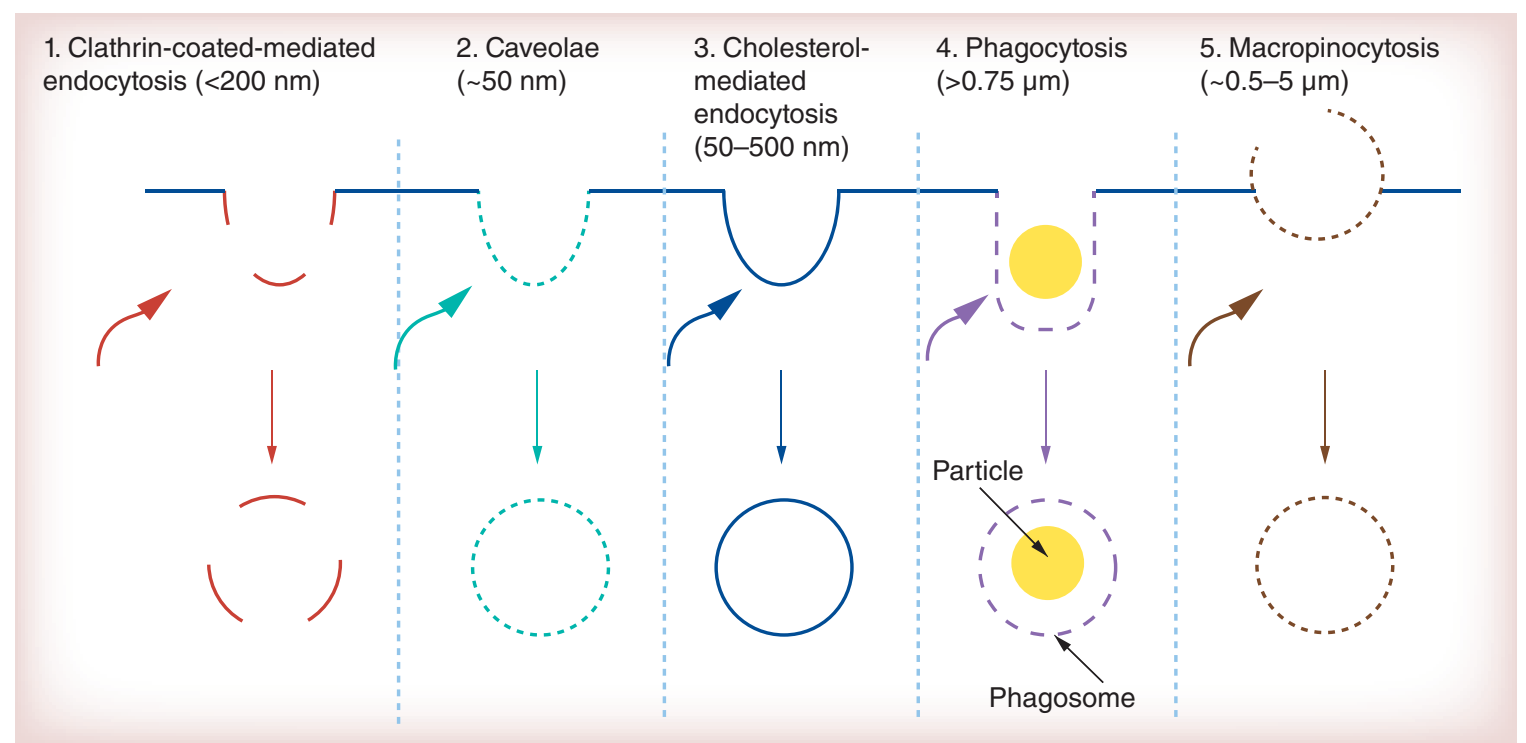

Figure 1. Particles internalization in the cell. Representation of different intracellular pathways of particle uptake. Uptake mechanisms differ depending on the size and nature of the nanoparticles.

While encapsulation within nanoparticles protects these therapeutics from the extracellular environment [15], after internalization the payload must be protected from intracellular endosomal digestion and be delivered to the cell cytoplasm. Methods devised to elude endosomal sequestration and 'conquer' the cytoplasmic space have led to a better understanding of cell physiology and trafficking, and to the development of therapeutic strategies aimed to specifically target and modulate the function of major subcellular compartments. Here we describe the strategies used to access the cell cytoplasm after internalization and to achieve organelle targeting, which in turn provides new means with which to treat various diseases. Finally, we pro-

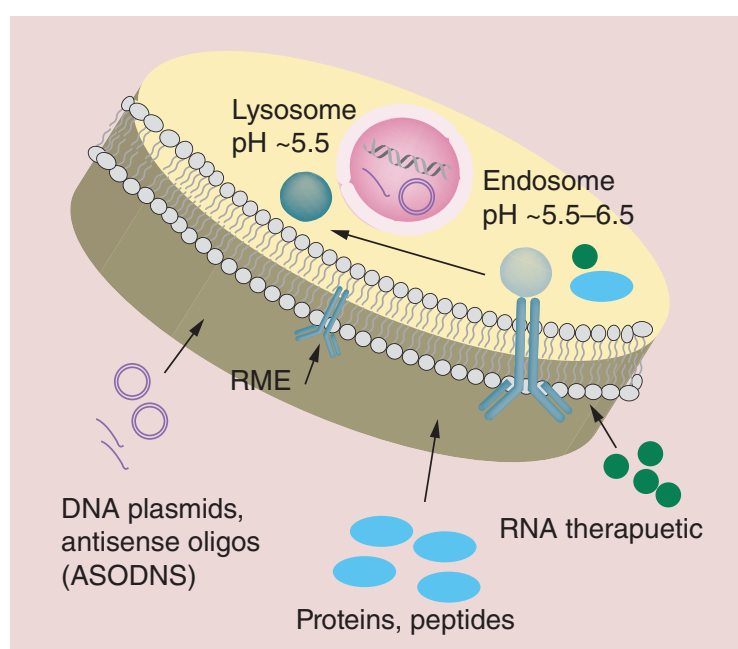

Figure 2. Endosomal barrier to intracellular delivery of therapeutic macromolecules.

ASODN: Antisense oligodeoxynucleotide; RME: Receptor-mediated endocytosis. vide examples of integrated systems that were designed to sequentially overcome several biological barriers and deliver the payload in the cytoplasm.

\section{Cell-penetrating peptides}

Protein translocation domains, also known as cellpenetrating peptides (CPPs), are short peptides able to cross biological membranes and deliver a wide variety of cargos into the cytoplasm $[16,17]$. They are usually divided into amphipathic peptides and polycationic peptides: the first contain an alternating pattern of polar and hydrophobic amino acids; while the second are rich in positively charged amino acids. In general, CPPs are characterized by an overall positive charge due to the abundance of arginine and lysine residues [16]. This positive charge favors their interactions with surface components of the cell membrane such as heparan sulfate and phospholipids that can act as CPP receptors [18,19], while hydrophobic residues like tryptophan increase the affinity for biological lipid structures [18]. Typical CPPs are the transactivator of transcription (TAT) peptide derived from HIV virus and the amphiphilic Antennapedia peptide derived from Drosophila [20].

The mechanism of CCP uptake is still unclear [21,22]. Various mechanisms have been proposed: energy-independent internalization mediated by local destabilization of the membrane structure rather than by intracellular endosomal trafficking [23]; uptake involving membrane lipid rafts and subsequent escape from these vesicles [16,24]; and macropinocytosis- and caveolaemediated endocytosis [25]. However, CPP internalization seems to depend on several factors, namely, their specific amino acid sequence [26]; the concentration of 
CPPs at the cellular interface (above a specific concentration threshold, they are internalized through nonendocytic pathways [27]); and the size of cargo fused to the CPPs [28]. These findings indicate that the transport of nanoparticles modified with CPPs occurs through energy-dependent endocytic pathways, in particular macropinocytosis [21].

The CPP surface functionalization of metallic, silica or lipid particles can be easily obtained by covalent modification or simple surface absorption driven by electrostatic bonds [29]. Using TAT-modified gold nanoparticles, Krpetic and co-workers were able to monitor and describe the intracellular trafficking of nanoparticles after endosomal escape [30]. They found that, after an initial phase of accumulation in the cytoplasm, nucleus and mitochondria, the particles were confined to vesicular bodies and eventually released again in the cytoplasm. The cytoplasmic delivery of specific payloads and materials was shown to enhance the anticancer properties of the system. Liu and colleagues showed that peritumoral injection of TATmodified silver nanoparticles efficiently inhibited multidrug resistance phenomena in vitro and in vivo [31]. Due to enhanced cellular uptake and a consequent increase in cellular drug accumulation, TAT-modified particles exerted a tumor growth inhibition power fourfold higher than unmodified particles [23].

CPPs have been also investigated for their capability to deliver drugs to the central nervous system. In fact, nanoparticles modified with TAT in combination with polyethylene glycol (PEG) favored brain accumulation and a higher penetration of the blood-brain barrier [32,33]. Although surface modification of particles with TAT does not ensure specific targeting of nervous tissue, TAT-modified particles can be used to treat severe diseases like brain tumors, thanks to their ability to accumulate in abnormal tumor vasculature [34].

\section{Antimicrobial peptides}

Antimicrobial peptides (AMPs) are a group of small amphipathic molecules (15-45 amino acids) characterized by a positive charge and, like CCPs, they have the ability to translocate within the cell cytoplasm. AMPs are produced by a wide variety of organisms of marine and terrestrial origin (including human defensins) $[35,36]$ as an essential component of their innate immune response [37]. Recently, Vale and co-workers [38] classified AMPs in function of their structure into four main categories: $\alpha$-helical peptides without Cys residues characterized by the presence of several Lys and Arg residues and a significant number of hydrophobic residues; $\beta$-pleated peptides containing disulfide bridges, for example, human defensins that are characterized by six Cys residues [39-41]; peptides rich in Pro, Gly, His,
Arg and Trp; and circular antimicrobial peptides. Antimicrobial peptides preferentially target viruses, bacteria and eukaryotic pathogens that are usually less anionic than mammalian cell membranes [27]. Thanks to these properties, AMPs can be used to modify nanoparticles designed to target microorganisms and achieve more efficient antibiotic effects.

To our knowledge, there are only two reports describing the production of AMP bioconjugates with nanoparticles [42,43]. Golubeva and coworkers [42] designed a nanoparticle with antimicrobial properties against Staphylococcus aureus and Pseudomonas aeruginosa by conjugating silver nanoparticles to peptide G-Bac3.4 (RFRLPFRRPPIRIHPPPFYPPFRPFL) modified from the natural peptide Bac3.4, which belongs to the bactenecin family. They showed that the modification process affected the membranolytic properties of the peptides. Yang et al. [43], on the other hand, produced liposomes conjugated with the antimicrobial peptide WLBU2 and loaded with the photosensitizer temoporfin. These liposomes effectively inhibited the proliferation of $S$. aureus and $P$. aeruginosa. Despite these promising results, the use of AMPs in the clinical setting is still limited by issues related to toxicity [44,45].

\section{Surface modification to avoid endosomal sequestration \& degradation}

\section{Endosomal sequestration of nanocarriers}

Despite many improvements in delivery systems $[1-4,46]$, the set-up of methods for the effective delivery of therapeutic biological agents such as proteins and nucleic acids remains a challenge $[5,47,48]$. One of the main limiting factors is that the endocytic pathway is the major uptake mechanism by which nanocarriers enter the cell [5]. This pathway is composed of endosomes that have an internal acidic $\mathrm{pH}$. These vesicles undergo a maturation process that, from early endosomes with a $\mathrm{pH}$ around 6, leads to late endosomes that have a $\mathrm{pH}$ around 5. Late endosomes can fuse with lysosomes that contain many digestive enzymes, namely, nucleases, proteases, glycosidase, lipases, phosphatases, sulfatases and phospholipases [12-14]. After entering the cell, nanovectors together with their payload become entrapped in endosomes after which they can enter lysosomes, where enzymatic processes degrade the payload especially if it comprises biological molecules (Figure 2). This route prevents efficient delivery of therapeutic agents to intracellular targets.

\section{$\mathrm{pH}$-responsive polymers as components of endosomolytic nanocarriers}

Many types of surface modifications of nanocarriers have been used to elude endosomal sequestration. The most frequently used procedures are based on 
molecules that induce osmotic lysis of the endosome through a pH-buffering effect known as the 'proton sponge effect' (Figure 3) [49,50]. The proton sponge effect of these molecules is based on their ability to accept $\mathrm{H}^{+}$ions at the acidic $\mathrm{pH}$ of the endosomes. The most promising candidate molecules in this context contain protonable secondary and/or tertiary amine groups that have a pKa close to the endosomal/lysosomal $\mathrm{pH}[12,43,44]$. Acidification of these endolysosomal vesicles occurs through specific endosomal $\mathrm{H}^{+}$ transmembrane pumps that work in symport with chlorine ions [43,44]. Molecules containing groups like tertiary amines that accept protons at a low $\mathrm{pH}$ are able to contrast vesicle acidification and to inhibit the negative molecular feedback that blocks the action of the endosomal pumps [49,50]. In response to the increased chloride concentration within the vesicle lumen, the osmotic pressure of endosomes increases [49,50] with a consequent incorporation of large amounts of water that, in turn, affects the endosomal ultrastructure thereby leading to osmotic swelling $[15,49,50]$ and subsequent membrane rupture. Poly(ethyleneimine) (PEI) [51,52], poly(amidoamine) (PANAM) [53,54] and poly (N, N-dimethylaminoethyl methacrylate) [5558] are among the polymers most often used to coat nanoparticles [56,59] to obtain delivery systems endowed with buffering properties that enable endosomal escape by the proton sponge effect.

Cytoplasmic delivery of biologicals can be improved even further by using other moieties to enhance the buffering ability of polymeric systems. A case in point is histidine, which is endowed with buffering properties thanks to its imidazole ring that has a $\mathrm{pKa}$ of around 6 , and that is protonated at a mildly acidic $\mathrm{pH}[12,60-63]$. Interestingly, polymers like polylysine and chitosan enriched in histidine significantly increased cytoplasmic delivery of nucleic acids [61].
Notably, in the case of polymers containing protonable amine groups (e.g., PEI and PANAM) or histidine residues, the proton sponge model may not be the only mechanism of endosomal escape. In fact, after protonation, the positively charged aminic groups could electrostatically bind the negatively charged endosomal membrane, which results in a physical interaction and subsequent fusion between the polymer and the endosomal membrane - a process that triggers the release of the payload into the cytoplasm [61-64]. For example, once protonated in an acidic environment, the $\mathrm{pH}$-sensitive polymer poly(histidine) acquires fusogenic properties thereby resulting in endosomal escape $[12,62]$. Other strategies to enable nanocarriers to elude endosomal sequestration are based on polymers with $\mathrm{pH}$-responsive properties resembling those of fusogenic peptides. For example, poly(propylacrylic acid) changes its conformation at a low $\mathrm{pH}$ thereby destabilizing the endosomal membrane and favoring delivery of the payload into the cell cytoplasm [65-67].

\section{Conjugation with peptides as a means to} enable nanocarriers to elude endosomal sequestration

Endosomal escape can be obtained by destabilizing the endosomal membrane. Various approaches to obtain destabilization of the endosomal membrane are based on the finding that viruses have evolved specific fusogenic proteins or peptides that mediate mechanisms for endosomal membrane penetration. These mechanisms consist in the fusion of the viral envelope with the lipid bilayer of the endosomal vesicles or the formation of pores through which the viral genome enters the cytosol [68,69]. In bacteria, the formation of pores in the endosomal membrane is the main mechanism of endosomal escape and it is mediated by bacterial exotoxins [70]. Also some animal and plant proteins are endowed with these

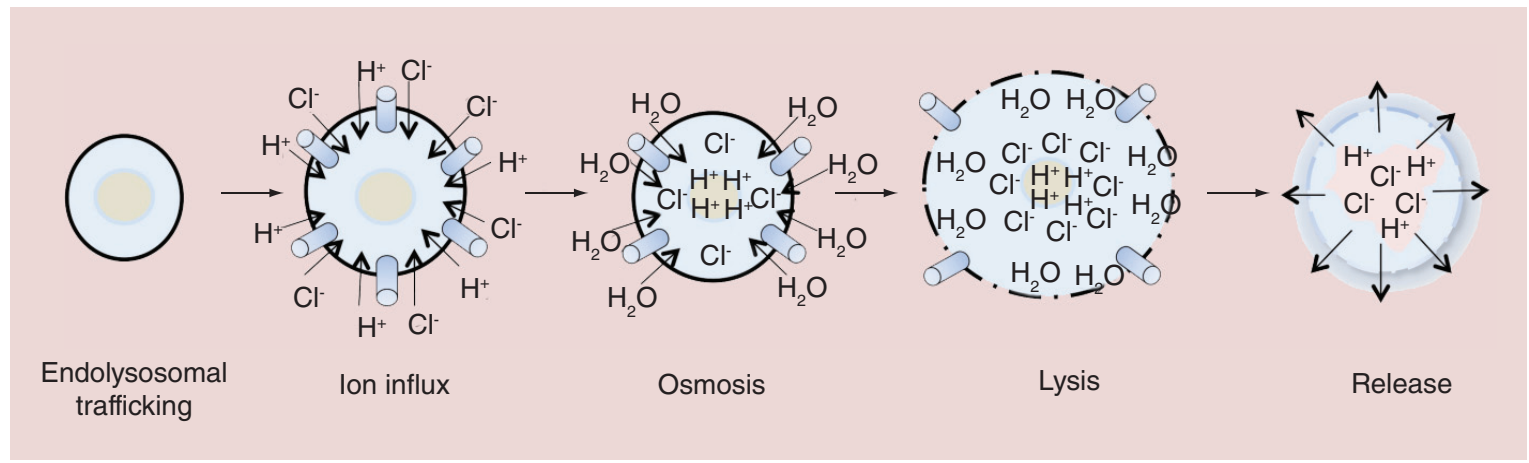

Figure 3. Endosomal escape by the proton sponge (pH-buffering) effect. Nanoparticles enter the cell and are trapped in endosomes. The membrane proton pumps continuously translocate protons into the endosomes. Particles become protonated and resist endosome acidification, thus more protons will be pumped into the endosomes thereby acidifying the environment. The proton pumping action is followed by passive entry of chloride ions into the endosomes, thereby increasing the ionic concentration and hence water influx. Due to the high osmotic pressure, the endosomes swell and break and consequently release their contents. 
types of fusogenic or membrane pore-forming properties [12]. In these mechanisms operating in nature, the acidic $\mathrm{pH}$ of endosomes triggers endosomal escape by inducing a change in the protein/peptide conformation and enabling interactions between the peptide and the lipid bilayer of the endosomal vesicles. In some cases, these peptides and protein domains form a random coil structure at physiological $\mathrm{pH}$, while at acidic $\mathrm{pH}$, some amino acid residues become protonated and peptides acquire an amphipathic $\alpha$-helical conformation [12]. In this condition, peptides can strongly interact with phospholipid membranes and can form pores or cause membrane fusion or lysis [71]. For example, Listeriolysin $\mathrm{O}$ is a toxin produced by the bacterium Listeria monocytogenes, which at acidic $\mathrm{pH}$ induces pore formation in cholesterol-containing lipid bilayers [72]. Listeriolysin $\mathrm{O}$ has been successfully used to favor the endosomal escape of liposomal nanocarriers [72]. The cationic peptide melittin is a component of bee venom, and forms amphipathic $\alpha$-helical structures that enter and destabilize the lipid membranes [73,74]. This peptide conferred endosomolytic properties to polymeric polyplexes [75].

Diphtheria toxin is secreted by Corynebacterium diphtheria. At acidic $\mathrm{pH}$, the $\mathrm{T}$ domain of this toxin changes its conformation and acquires fusogenic properties [70]. The conjugation of this peptide to polyplexes enhances their endosomal escape capability [76]. The $\mathrm{pH}$-responsive fusogenic peptides KALA, GALA and INF-7 are derived from the N-terminal domain of influenza virus hemagglutinin HA-2 subunit. They have been successfully used to facilitate the endosomal escape of lipidic and polymeric carriers of nucleic acids, proteins and drugs [54-58,77-85,115,117-119].

\section{$\mathrm{pH}$-responsive lipids as components of endosomolytic nanocarriers}

Some nanoformulations of lipids are used to obtain nanocarriers able to escape from endosomes and to deliver active payloads in the cell cytoplasm. Cationic lipids can electrostatically interact with negatively charged lipids of the cytosolic layer of the endosomal vesicle and exert a moderate fusogenic effect $[60,61]$. To increase their efficiency in endosomal membrane destabilization, helper lipids like $\mathrm{L}-\alpha$-di-oleoyl phosphatidyl ethanolamine can be added to the lipid formulation [86]. The ethanolamine head group of L- $\alpha$-di-oleoyl phosphatidyl ethanolamine has a high tendency to form an inverted hexagonal phase at acidic $\mathrm{pH}$ which, in turn, improves fusogenicity [60,61] .

Also lipids with histidine or imidazole moieties can increase the $\mathrm{pH}$-responsiveness of nanovectors and endow them with proton sponge abilities, fusogenic properties or both. For example, nanocarriers constituted by 1,5 -distearyl $N$-( $N$-a-(4-mPEG2000)
butanedione)-histidyl-L-glutamate [87], or by imidazole-bearing 1,4,7,10-tetraazacyclododecanes (cyclen)based cationic lipids [88] increased the efficacy of the cytoplasmic delivery of a payload and enabled endosomal escape mainly through a proton sponge mechanism [82]. Liposomes made with dioleyl succinyl paromomycin: $O, O$-dioleyl- $N$-histamine phosphoramidate [89], or with $O, O$-dioleyl- $N$-[3N-(N-methylimidazolium iodide)propylene] phosphoramidate and $O, O$ dioleyl- $N$-histamine phosphoramidate [90] can release their cargo outside endosomes probably by both proton sponge and fusogenic mechanisms.

\section{Organelle targeting}

In many cases, the success of any delivery system greatly depends on the capability of the carrier to transport the cargo to its specific site of action within the cell cytoplasm. For instance, all DNA carriers must overcome the nuclear membrane to exert their function. Consequently, the development of approaches aimed at effectively targeting the cellular organelles (nucleus, mitochondria and endoplasmic reticulum [ER]) and subsequently, delivering the payload in its active status directly to its intracellular site of action is a fundamental step in the development of more effective therapeutics (Figure 4). In the following sections, we discuss the strategies used to modify the surface of nanoparticles in order to ensure subcellular delivery of payloads. Nuclear, mitochondrial and ER targeting is particularly complex given the importance of these organelles for cell physiology. In fact, loss of function of one of these organelles causes various pathological conditions (see Table 1).

\section{Nuclear targeting}

The nucleus is surrounded by a double-layered membrane punctured by protein channels, known as the nuclear pore complex, that determine the in and out' trafficking between the nucleus and the cytoplasm [91,92]. Learning how to enhance nuclear delivery has great scientific and translational relevance because the nucleus governs cell physiology by controlling replication and transcription processes, and it is the final functional target of many therapeutic approaches (e.g., gene therapy). In fact, the nucleus is responsible for all diseases derived from a mutation of a gene (at the level of both the promoter and the splicing site), including heart dysfunction [93], muscular dystrophy [94] and neurodegenerative disease [95]. In addition, transport through the nuclear membrane is essential for all anticancer agents whose cytotoxic action is based on DNA intercalation (e.g., doxorubicin and cyclophosphamide).

Unfortunately, the nuclear membrane is difficult to penetrate and nanoparticles rarely accumulate in this 


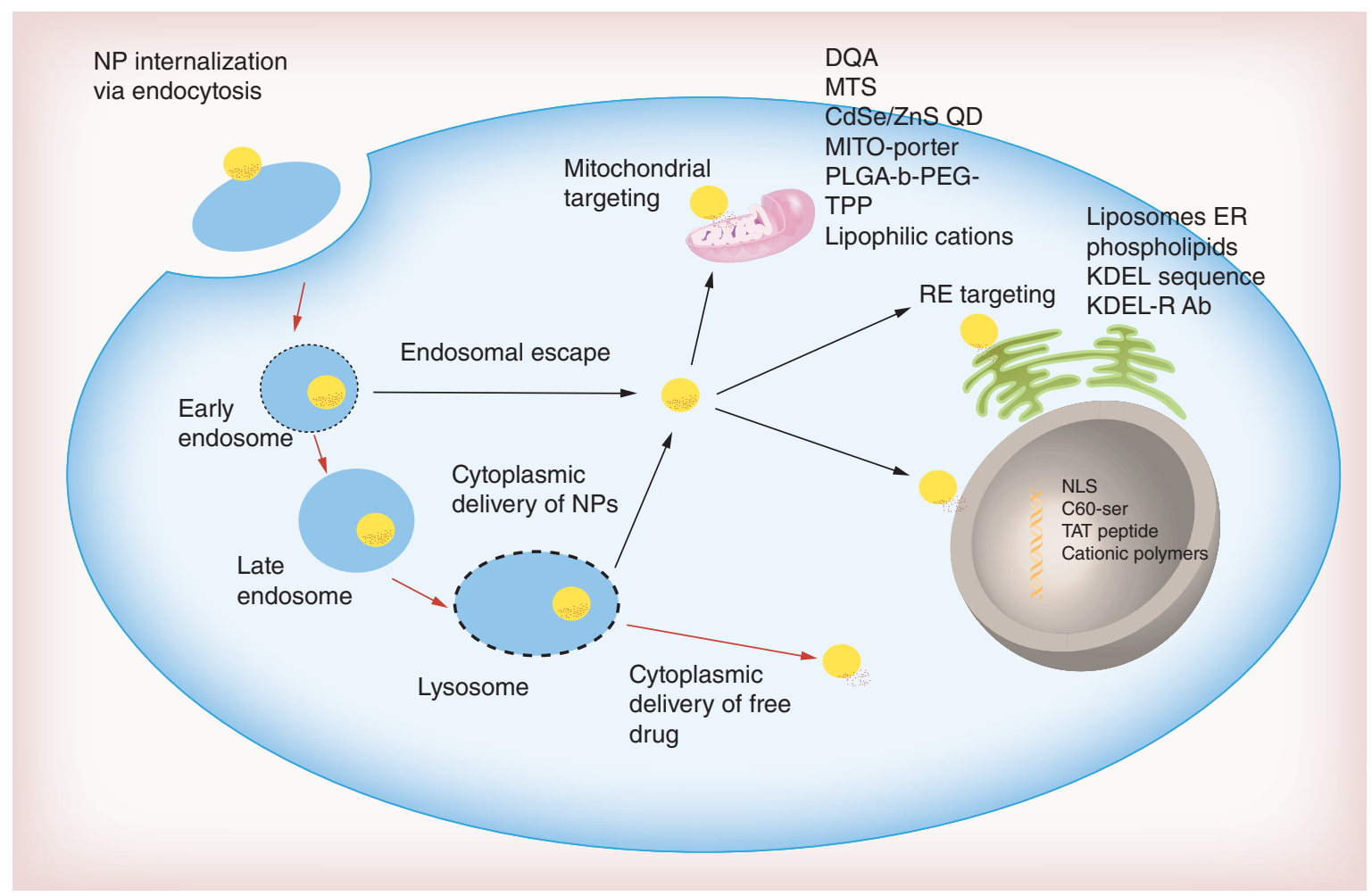

Figure 4. Intracellular drug delivery. Cytosolic delivery and targeting of the nucleus, the mitochondrion and the endoplasmic reticulum.

ER: Endoplasmic reticulum; NP: Nanoparticle; NLS: Nuclear localization signal.

organelle [96-99]. Indeed, the small pore size of the nuclear membrane $(\approx 10 \mathrm{~nm})$ prevents the passage of molecules larger than $40 \mathrm{kDa}$ even when the pores are dilated [100]. Consequently, large molecules must be actively transported beyond the membrane by proteins. The functionalization of nanoparticles with nuclear localization signals (NLS), which are characterized by basic amino acid residues, implies the recognition of the NLS by its cytoplasmic receptors, such as importins. Subsequently, the NLS peptide binds the nuclear pore

Table 1. Organelle-associated diseases.

\begin{tabular}{|llr|}
\hline Organelle & Associated diseases & Ref. \\
& Heart dysfunction & {$[93]$} \\
& Muscular dystrophy & {$[94]$} \\
& $\begin{array}{l}\text { Neurodegenerative } \\
\text { disease }\end{array}$ & {$[95]$} \\
Mitochondrion & Neurodegeneration & {$[123,124]$} \\
& Cancer & {$[122]$} \\
& Diabetes mellitus and & {$[125]$} \\
& deafness & \\
Endoplasmic & Cardiomyopathy & {$[121]$} \\
reticulum & Neurodegeneration & {$[149]$} \\
& Cancer & {$[150]$} \\
& Diabetes & {$[151]$} \\
& Cardiovascular & {$[152]$} \\
& disease & \\
\hline
\end{tabular}

complex and the cargo is released into the nucleus via translocation through the pores [101]. Considering that the pore size of nuclei is usually smaller than that of typical drug delivery systems, it appears that the diffusion of nanoparticles (not confined in intracellular vesicles) depends on the carrier size in the case of passive transport, and on the inclusion of an NLS in the case of active transport [102]. An example of a drug delivery system developed to target the nucleus by passive transport is represented by malonodiserinolamide fullerene $\mathrm{C}_{60}(\mathrm{C} 60$-ser, 3-4 nm) nanoparticles, fabricated to treat liver cancer in vivo. Thanks to their small size, they were found to localize in the nucleus by diffusion through the nuclear pore complex [103]. Also nanoparticles surface-modified with NLS have been widely used to target genes to the nucleus. Particles modified with the KKKRKV peptide from the Simian virus 40 large tumor antigene, or peptide KRPAATKKAGQAKKKKL from nucleoplasmin (an enzyme involved in nucleosome assembly) accumulated in much larger amounts in the nuclear membrane than did unmodified controls. [97,104-110]. Nuclear localization signals exerted an efficient translocation function also when they were integrated in a classical PEG coating that enabled gold nanoparticles to inhibit the division of cancer cells [111] as well as to avoid unspecific interactions with other biological entities. Notably, Mackey and collaborators 
showed that NLS-labeled gold nanoparticles had a specifically enhanced cytotoxic effect on cancer cells [112]. The HIV-1 TAT peptide is a well-known nuclear membrane translocator, which when applied on the surface of nanoparticles enables them to elude endosomal sequestration and to accumulate in the nucleus $[18,113]$. Notably, doxorubicin exerted stronger anticancer activity when it was encapsulated in mesoporous silica particles whose surface was modified with the TAT peptide [97,104-106,114,115]. Nuclear targeting can also be accomplished by exploiting the high affinity of acridin to DNA. Acridine-based compounds can reversibly bind DNA through intercalation and act as phototriggers for the controlled release of drugs. Acridin-9-methanol-functionalized nanoparticles were shown to accumulate in the nucleus of HeLa cells [109]. Consequently, photoresponsive acridin-conjugated nanoparticles can be used to control drug release into nuclei [116]. In other nuclear targeting strategies, a positive charge was applied to the particle surface. Cationic polymers such as PEI and poly (L-tartaramidoamine) increased the targeting of particles to the nuclear membrane, probably thanks to their ability to permeabilize the nuclear envelope - a process that favors proper delivery of pDNA payloads to the nuclei of target cells $[117,118]$.

Finally, an interesting approach was based on the targeting of specific cell receptors to induce both cellular internalization and nuclear translocation. EGFR is located on the cell membrane and once activated it accumulates in the cell nucleus thanks to the action of karyopherin- $\beta^{67}$, a protein responsible for the transport of cytoplasmic material to the nucleus. Importantly, EGFR has great clinical relevance because its nuclear translocation occurs mainly in cancer cells. $\mathrm{Fe}_{3} \mathrm{O}_{4} @ \mathrm{TiO}_{2}$ nanoparticles conjugated with EGFRbinding peptides showed better nuclear localization in EGFR-expressing HeLa cells than control nanoparticles [119].

\section{Mitochondrial targeting}

Mitochondria are characterized by an outer and an inner membrane enriched in protein. The two membranes determine the formation of two separate compartments: the intermembrane space and the mitochondrial matrix. These organelles possess their own DNA, which is organized in several copies of a single, circular chromosome [120]. Mitochondria are involved in apoptotic cell death, adenosine triphosphate synthesis, production of reactive oxygen species and calcium metabolism. Consequently, mitochondrial dysfunction has been associated with a variety of disorders (cancer, neurodegenerative diseases, cardiovascular disease and diabetes) [121-125] and they have been extensively studied as therapeutic intracellular targets. The main rea- son why strategies to achieve targeted mitochondrial drug delivery were developed is that chemotherapeutics act directly on mitochondrial function and favor apoptosis. Two generalized requirements for mitochondrial localization are lipophilicity and delocalized positive charge. Increasing doxorubicin lipophilicity by introducing a nitric oxide into the molecule (nitroxydoxorubicin) [126] shifts the intracellular localization to mitochondria and to the ER [127].

The large mitochondrial membrane potential (negative inside) can be exploited to target mitochondriamodifying particles or bioactive molecules using positively charged molecules; Schiller-Szeto peptides are a combined series of hydrophobic and positively charged tetrapeptides that severely localize to mitochondria [128]. Lipophilic cations such as rhodamine, triphenylphosphonium (TPP) and stearyl triphenylphosphonium were shown to increase liposome mitochondria targeting $[129,130]$. To avoid issues of the nonspecific cytotoxicity of stearyl triphenylphosphonium liposomes, Biswas et al. synthesized a novel coating of polyethylene glycol-phosphatidylethanolamine conjugated with the TPP group attached to the distal end of the PEG block (TPP-PEG-PE) [104]. Similarly, Marrache et al. designed a mitochondria-targeted polymeric nanoparticle system by blending a targeted poly(D,L-lactic-coglycolic acid)-block (PLGA-b)-poly(ethyleneglycol) (PEG)-triphenylphosphonium (TPP) polymer (PLGAb-PEG-TPP) with b-poly(lactide-co-glycolide)-succinic acid (PLGA-COOH) or with PLGA-b-PEG-OH. They varied the size and the surface charge of nanoparticles in an attempt to understand the effect of these properties on mitochondrial uptake [131]. Mitochondrial uptake was studied by qualitative and quantitative investigations of the cytosolic and mitochondrial fractions of cells treated with these blended nanoparticles [131]. Evaluation of the mitochondrial uptake of nanoparticles measuring $80-330 \mathrm{~nm}$ revealed a trend toward a maximum uptake of particles between 80 and $100 \mathrm{~nm}$ in diameter. Among hydrodynamic particles of a similar diameter but with different surface charges, mitochondrial uptake increased significantly with the more positively charged nanoparticles.

Strategies inspired by intracellular trafficking of mitochondrial proteins were developed by modifying nanoparticles with the mitochondrial targeting signal, 10-70 amino acids). In the cell, the mitochondrial targeting signal directs newly synthesized proteins to the mitochondria. Hoshino et al. described the ability to direct the uptake and localization of CdSe/ZnS Quantum Dots to the mitochondria using the mitochondrialtargeting peptide (Mito-8, sequenced MSVLTPLLLRGLT-GSARRLPVPRAKIHWLC) derived from cytochrome- $c$ oxidase (a component of the electron 
transport chain) [132]. Various approaches, based on specific materials, have been used to deliver DNA to mitochondria in the attempt to improve therapies for mitochondria-associated diseases. For example, the liposome-like vesicles delocalized lipophilic cation dequalinium (DQA)-somes, which are characterized by a positive charge, showed high affinity for the mitochondrial membrane [133,134]. These vesicles are made of dequalinum chloride, a mitochondiotropic delocalized cation that severely accumulates in the mitochondria of carcinoma cells [135].

Similar strategies are based on surface-modified resveratrol liposomes co-conjugated with dequalinium polyethylene glycol-distearoylphosphatidylethanolamine (DQA-PEG2000-DSPE). This delivery platform exerted antitumor effects in various tumor models in vitro and in vivo [136]. Yamada et al. developed a liposome with fusogenic properties called 'MITO-porter' designed for mitochondrial gene delivery that enabled efficient targeting of the innermost mitochondrial space $[137,138]$. More recently, the same group increased the efficacy of this system by producing liposomes with a double lipid shell to sequentially penetrate cell and mitochondrial membranes, thereby avoiding endosomal sequestration (dual function MITO-Porter) [139]. Xia Yang et al. synthesized a new kind of fluorescent core-shell ellipsoidal-ionic liquid nanoparticle that has anticancer activity and that can be used in imaging techniques [29]. These particles were taken up by HeLa cells through a mitochondriaassociated pathway favored by a functional ionic liquid (acetyl- $N$-butyl pyridinium hexafluorophosphate) conjugated to rhodamine B isothiocyanate-doped silica-coated [29]. Agemy et al. developed iron oxide nanoworms modified in their surface with a tumor-homing peptide (CGKRK), which enabled mitochondrial targeting, and a proapoptotic peptide (D[KLAKLAK $] 2)$, which ensured tumor cell killing in a murine glioblastoma [140]. Wang et al. observed that Au nanorods coated with a cetyltrimethylammonium bromide bilayer and serum components was preferentially uptaken by cancer cells (compared with normal cells) and mitochondrial targeting ability [46]. Mo and collegues reported that $\mathrm{pH}$-sensitive liposomes $\left(\mathrm{HHG}_{2} \mathrm{C}_{18}-\mathrm{L}\right.$ and PEGHG2C18-L) based on zwitterionic oligopeptide lipids as anticancer drug carriers were developed and evaluated for effective intracellular delivery and enhanced antitumor activity [87]. Liposomes modified with 1,5-dioctadecyl-l-glutamyl 2-histidyl-hexahydrobenzoic acid $\left(\mathrm{HHG}_{2} \mathrm{C}_{18}-\mathrm{L}\right)$ and 1,5-distearyl $N$-(N-a-(4-mPEG2000) butanedione)-histidyl-L-glutamate (PEGHG2C18) are able to escape endosomal sequestration and target mitochondria by reversing their surface charge in function of the difference in
$\mathrm{pH}$ between endosomal vesicles and cytoplasm [87]. The His groups play a key role in endosomes/lysosome escape. The imidazole ring of histidine is a weak base that has the ability to acquire a cationic charge when the $\mathrm{pH}$ of the environment drops below 6 . The accumulation of histidine residues in acidic vesicles can increase their osmolarity and their swelling [141144]. HHG2C18 and PEGHG2C18 liposomes exploit the property to develop the proton sponge effect that enables liposomes to be released from the endosome membrane-bound compartments [87].

\section{ER targeting}

The ER is organized in a membrane network of sac-like structures called 'cisternae,' and an intra- and extra-cisternae space is discernible in its volume. The ER governs such important cell functions as protein folding and lipid biosynthesis [145]. In addition, it controls calcium homeostasis [146], apoptosis [147] and drug detoxification biochemical pathways [148]. ER stress leads to protein misfolding and/or aggregation, and these phenomena are often associated with such disorders as neurodegeneration [149], cancer [150], diabetes [151] and cardiovascular disease [152], which highlights the importance of targeting this organelle. Physiologically, protein trafficking to the ER is mediated by the KDEL sequence and its receptor (KDEL-R) expressed on this organelle. This sequence is an ER localization signal and was used to improve the intracellular targeting of these organelles [153]. Acharya and Hill developed gold nanoparticles conjugated with the KDEL peptide for the delivery of siRNA that inhibits the expression of reduced nicotinamide adenine dinucleotide phosphate oxidase 4 [154]. This strategy was shown to be more efficient than lipofectamine in transfecting differentiated myotubes. Delie and coworkers developed anti-KDEL functionalized polymeric nanoparticles loaded with paclitaxel for the treatment of prostate cancer [155]. They demonstrated that ER targeting significantly increased paclitaxel sensitivity in prostate cancer cells overexpressing G-protein-coupled receptor 78. There is evidence that ER targeting improves vaccine formulations for cancer immunotherapy [156]. In fact, in antigen-presenting cells, the antigens bind the major histocompatibility complex class-I molecules in the ER [157]. The research group of Nakagawa assembled fusogenic liposomes loaded with tumor antigen peptides coated with an ER-insertion signal sequence, which efficiently induced in vivo tumor immunity [158]. Compared with untargeted peptide-loaded fusogenic liposomes, these carriers prolonged epitope presentation in antigenpresenting cells for up to $140 \mathrm{~h}$ [158]. Finally, Pollock and coworkers developed a biomimetic approach based on liposomes synthesized with the same phospholipid 
composition as ER vesicles (57\% phosphatidyl choline, $24 \%$ phosphatidyl-ethanolamine, $13 \%$ phosphatidylinositol, 3\% phosphatidyl-serine and 3\% sphingomyelin [159]), and demonstrated significant co-localization of these particles with the ER compartment within $30 \min [160]$.

\section{Integrated approaches}

As mentioned above, to reach the cytosol, nanocarriers must usually overcome several biological barriers that differ in terms of architecture, working mechanism and composition [5]. Traditional injectable delivery platforms are designed to accumulate in the diseased area by exploiting the enhanced permeability and retention effect [161]. Particle surface modification with PEG is the most common way to exploit this effect since PEG enables the formation of a hydrodynamic radius that shields and protects the particles from intimate interaction with biological entities [162,163]. In particular, PEG proved to be very efficient in delaying particle opsonization, which favors the entrapment of particles into reticulo-endothelial system organs and their clearance [164]. Unfortunately, the stealthing action of PEG hinders the targeting and penetrating action of the molecules applied on the surface of the particles. Multiple surface modifications (with, e.g., PEG + targeting molecules + cell-penetrating peptides) to sequentially overcome the biological barriers separating the administration site from the target area can be made by appropriately dosing the different particle constituents and applying, when possible, synthesis approaches that preserve the structure of biological molecules, such as surface absorption through electrostatic interactions [165]. On the other hand, the use of multiple surface modifications to confer several functionalities to the carriers could increase the complexity of chemical synthesis, production costs and the number of potential side effects of the system, thereby making the translation of these technologies to the clinical setting extremely difficult [166]. The advent of polymers or particles with buffering properties could overcome these issues because endosomal escape is achieved through a mechanism that resides in the polymer/particle structure rather than on their surface. In addition, the surface of polymeric particles can be modified with shielding molecules to prolong particle circulation time, or with targeting agents.

Few attempts have been made to enable synthetic particles to sequentially overcome different biological barriers. Multistage silicon systems developed by the group of M. Ferrari for example are constituted by a first stage of nanoporous silicon that can be loaded with second-stage nanocarriers [167]. The shape of these particles was designed to marginate within tumor capillaries where the blood flow decreases and their structure dissolves in the biological fluid so that the second-stage nanoparticles are released within the tumor vasculature. These particles can be endowed with an endosomal escape mechanism and efficiently deliver siRNA to the tumor cell [168]. In addition, there is evidence that porous silicon and silica could exert a proton sponge effect thereby favoring the cytoplasmic delivery of siRNA. However, the integration of these multistage particles with $\mathrm{pH}$-responsive polymers improved the delivery of biologicals [169], which shows successful integration of functions.

The negotiation of biological barriers through bioinspired approaches has recently gained momentum. These strategies are typically based on viral peptides with fusogenic and intracellular targeting properties [170]. Our group proposed a biomimetic approach based on coating synthetic particles with purified cell membrane of infiltrating leukocytes [171]. Using this strategy, the surface of nanocarriers was enriched, in a single step, with a natural membrane coating enriched with more than 150 leukocyte membrane-associated proteins [172] that determine reduced unspecific binding of opsonizing agents, improved biocompatibility and self-tolerance and local increase of inflamed vasculature targeting and permeability. In addition, once internalized within endothelial cells, particles coated with the leukocyte cell membrane were able to avoid endolysosomal sequestration (Figure 5), probably as a result of fusogenic phenomena of the membrane coating toward endosomal vesicles or of the activation of an alternative internalization pathway (e.g., caveolin-

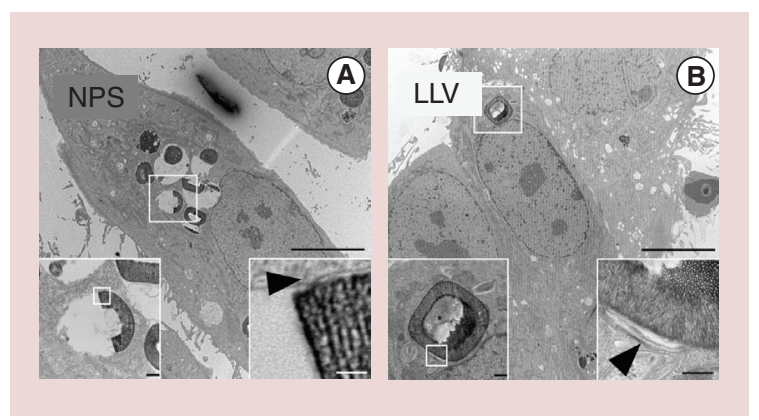

Figure 5. Intracellular trafficking of nanoparticles and leuko-like vectors. Human umbilical vein endothelial cells seeded on fibronectin and activated for $24 \mathrm{~h}$ with TNF- $\alpha$ were treated with (A) nanoparticles and (B) LLVs. Transmission electron micrographs showing lysosomal sequestration and cytoplasmic accumulation of nanoparticles and LLVs, respectively, $6 \mathrm{~h}$ after treatment with the particles. High-magnification images are shown on the right. Scale bars: $10 \mathrm{~mm}$ (main boxes), $500 \mathrm{~nm}$ (left insets) and $100 \mathrm{~nm}$ (right insets). NP: Nanoparticle; LLV: Leuko-like vector.

Adapted with permission from Parodi et al. [173]

(c) Nature Publishing Group (2013). 
(A)

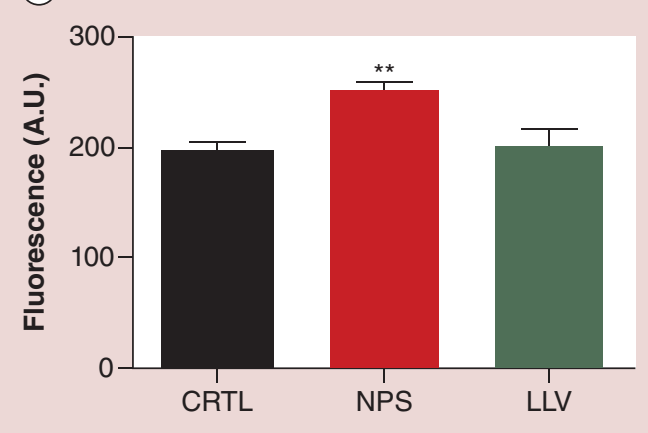

(C)

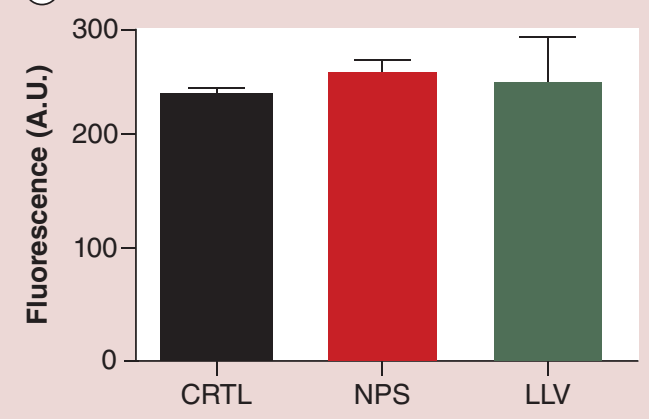

(B)
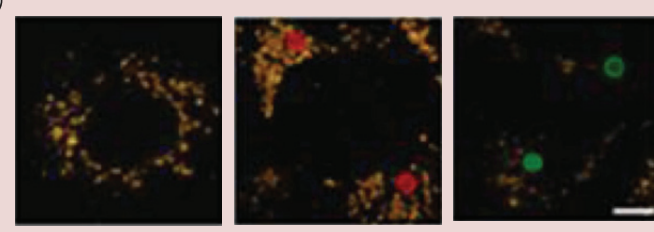

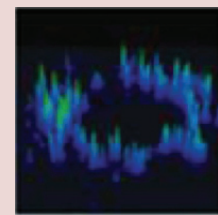

CRTL

(D)
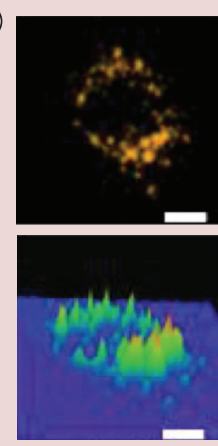

CRTL

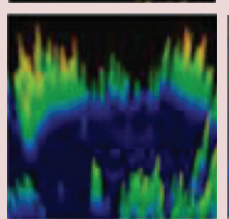

NPs
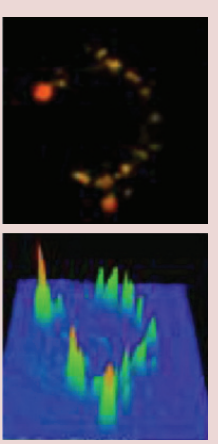

NPs

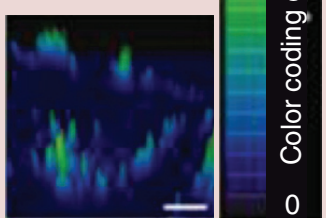

LLV

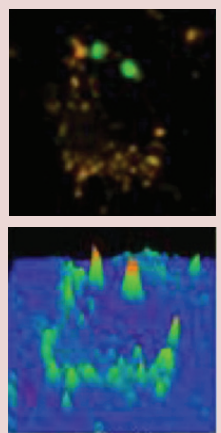

LLV

Figure 6. Lysosomal activity after incubation in an endothelial monolayer in inflammatory conditions.

(A) Quantification of the Lysotracker Red lysosomal staining detected in the confocal samples after $3 \mathrm{~h}$ of incubation. Experiments were performed in triplicate and three fields were randomly chosen and analyzed for each condition. Significance was calculated with one-way Anova followed by Dunnett's test. All standard deviations refer to three independent experiments with ${ }^{* *} p<0.01$. (B) Confocal images of inflamed endothelial cells seeded on fibronectin and incubated with NPs and LLVs for $3 \mathrm{~h}$. The intensity plots show the cellular lysosomal activity of untreated and NPs- and LLV-treated cells. Scale bar $=5 \mu \mathrm{m}$. (C) Quantification of the Lysotracker Red lysosomal staining detected in the confocal samples after $24 \mathrm{~h}$ of incubation. Experiments were performed in triplicate and three fields were randomly chosen and analyzed for each condition. Significance was calculated with one-way ANOVAs followed by Dunnett's test. All standard deviations refer to three independent experiments. (D) Confocal images of inflamed endothelial cells seeded on fibronectin and incubated with nanoparticles and LLVs for $24 \mathrm{~h}$. The intensity plots showed the cellular lysosomal activity of untreated and NPsand LLV-treated cells.

Scale bar $=5 \mu \mathrm{m}$.

CTRL: Control; LLV: Leuko-like vector; NP: Nanoparticle.

Adapted with permission from Parodi et al. [173] @ Nature Publishing Group (2013).

driven internalization; data under investigation). As shown in Figure 5, leukolike vectors (LLVs) retain their leukocyte membrane (black arrow, right inset) and are in contact with the cytoplasm, while nanoparticles are trapped in the endolysosomal compartment (black arrow, left insert). This phenomenon was quantified by measuring the internalization of the specific probe Lysotracker Red. As shown by our group and others [173-176], internalization of nanoparticles induces increased accumulation of this dye within the cells (Figure 6). A higher uptake of Lysotracker Red (or other probes specific for the endosomal compartment) was observed a few hours after internalization of uncoated particles, whereas treatment with LLV did not induce the same effect (Figure 6A \& B). At longer time points after treatment, accumulation of the dye did not differ between cells treated with uncoated particles and LLV-treated cells because the internalization process returned to basal level (Figure 6C \& D).

In this context, Harashima's group developed a tetra-lamellar multifunctional envelope-type nanodevice [176], inspired by the biology of adenovirus $[107,108,177,178]$. Thanks to the bioactivity of its surface, the system efficiently negotiated multiple extra- and intra-cellular barriers to delivery and to diagnostic applications. 


\section{Conclusion}

A plethora of strategies have been devised to enable synthetic particles (and their payload) to escape endosomal sequestration and target different subcellular compartments. These strategies can be achieved through nanoformulation of $\mathrm{pH}$-responsive polymers or lipids or the conjugation of $\mathrm{pH}$-responsive polymers or peptides on the surface of drug delivery carriers thereby endowing them with the ability to respond to the surrounding environment. Here we describe several approaches that can be used to enable particles to easily access the cytoplasm, and to target the nucleus, mitochondria and ER. Organelle targeting is usually mediated by peptide sequences that increase the affinity of carriers toward the intracellular compartments (Table 2). Nonetheless, endosomal escape and intracellular targeting are only the final steps of the delivery process. Targeting approaches can be classified in three main categories: primary targeting defined as accumulation of the delivery system in the tissue of interest; secondary targeting defined as accumulation in the cell of interest; and tertiary targeting defined as targeting specific subcellular compartments. Tertiary targeting is the ultimate challenge of nanomedicine and so far, strategies that enable particle diffusion in the cytosol have resulted in a deeper understanding of the biological processes that govern intracellular trafficking, but their clinical application remains limited because of the difficulty in designing nanocarriers that combine all the targeting steps.

\section{Future perspective}

Enormous effort is still required to integrate in a single technology the various approaches to sequentially overcome all the biological barriers that are encountered in the route to the target. In addition, these technologies must have a high reproducibility and cost-effective standards of production in order to favor their clinical translation. The development of new synthesis techniques as well as the new bio-inspired approaches could play a key role in the clinical translation of technologies designed to achieve cytoplasmic delivery of the payload and organelle targeting.

\section{Summary}

This review is devoted to the most recent advances in subcellular targeting and the development of new therapeutic strategies able to specifically target and modulate the function of major subcellular compartments. We also describe the approaches used to access the cell cytoplasm after particle internalization and to achieve organelle-targeting, and provide some examples of novel integrated systems designed to sequentially overcome more than one biological barrier. In this context, we review recent data about the new strategies used to enable nanocarriers to cross cellular barriers using cell-penetrating peptides, and to avoid endosomal sequestration through smart polymer modification. Last, we describe recent discoveries in the field of nuclear, mitochondrial and ER targeting. Considering that these organelles are the final target for a wide variety of therapeutic molecules, specific subcellular targeting is the ultimate challenge of nanomedicine and much effort is being spent to shed light on the processes that govern the intracellular trafficking of nanoparticles.

\section{Acknowledgements}

The authors thank Jean Ann Gilder (Scientific Communication spa, Naples, Italy) for editing the text.

\section{Author contribution}

All authors have contributed to the manuscript and have given approval to the final version of the manuscript.

Table 2. Peptides and their targeting organelles reported in this review.

\begin{tabular}{|llr|}
\hline Organelle & Peptide sequence & Ref. \\
Nucleus & (SV40 T antigene) KKKRKV & {$[97,104-110]$} \\
& KRPAAT KKAGQAKKKKL & \\
& $($ HIV-1 TAT) GRKKRRQRRRPQ & {$[18,113]$} \\
& DOPAC-MYIEALDKYAC-COOH & {$[119]$} \\
\hline Mitochondrion & MSVLTPLLLRGLT-GSARRLPVPRAKIHWLC & {$[132]$} \\
& GKRK & {$[140]$} \\
& D[KLAKLAK]2 & {$[128]$} \\
& SCHILLER-SZETO (SS) tetrapeptides. SS-02: (Dmt-RFK); SS-20 (FRFK); \\
& SS-31 (R-Dmt-KF) & {$[153]$} \\
\hline Endoplasmic reticulum & KDEL & \\
\hline DMT: 2,6-dimethyltyrosine; DOPAC: 3,4-dhydroxyphenylacetic acid; TAT: Transactivator of transcription. & \\
\hline
\end{tabular}


Financial \& competing interests disclosure

This work was supported by grants RF-2010-2318372 and RF2010-2305526 from Italian Ministry of Health, and by grants 1R21CA173579-01A1 from NIH/NCl, 5U54CA143837 PSOC Pilot project from NIH/NCl, W81XWH-12-10414 BCRP Innovator Expansion from Department of Defence, and The Regenerative Medicine Program Cullen Trust for Health Care to E Tasciotti. We thank the Associazione Bianca Garavaglia, Via C. Cattaneo, 8, 21052 Busto Arsizio Varese, Italy and Project CREME "Campania Research in Experimental Medicine" POR Campania FSE $2007 / 2013$. The authors have no other relevant affiliations or financial involvement with any organization or entity with a financial interest in or financial conflict with the subject matter or materials discussed in the manuscript apart from those disclosed. No writing assistance was utilized in the production of this manuscript.

\section{Open access}

This work is licensed under the Attribution-NonCommercialNoDerivatives 4.0 Unported License. To view a copy of this license, visit http://creativecommons.org/licenses/by-nc$\mathrm{nd} / 4.0 /$

Executive summary

\section{Cell-penetrating peptides}

- Nanoparticles modified with cell-penetrating peptides (CPPs), for example, transactivator of transcriptionmodified nanoparticles, are able to enhance cellular uptake and increase cellular drug accumulation thereby improving the anticancer proprieties of the described systems. CPP modifications can favor penetration of the blood-brain barrier.

\section{Surface modification to avoid endosomal sequestration \& degradation}

- $\mathrm{pH}$-responsive molecules used as constituents of nanocarriers favor the rupture of the endo/lysosomal membrane thereby resulting in the release of the carriers and their payload into the cell.

Nuclear targeting

- The pore size of nuclei is usually smaller than drug delivery systems, some nanoparticles, for example, $C_{60}$, are small enough to diffuse through these pores. Another approach to nuclear targeting is to functionalize the nanoparticle with nuclear localization signals. Nuclear targeting can also be accomplished by exploiting the high affinity of acridine for DNA or by applying a positive charge to the nuclear membrane.

\section{Mitochondrial targeting}

- Requirements for mitochondrial targeting are lipophilicity and delocalized positive charge. Nitroxydoxorubicine, Shiller-Szeto peptides, lipophilic cations and DQAsomes, overcome the need for these characteristics. Other strategies are based on modifying nanoparticles with the mitochondrial target signals, in other words, small peptides from 10 to 70 amino acids. Another approach, peptide-based, is the MITO-porter system, which was designed for mitochondrial gene delivery.

\section{Endoplasmic reticulum targeting}

- Strategies to target the endoplasmic reticulum (ER) are based on conjugating ER localization signals (small peptides) or antibodies against its receptor to nanoparticles. Recent studies show that ER targeting improves the efficacy of vaccines for cancer immunotherapy. The latest biomimetic strategies devised to target the ER are based on liposomes that have the same phospholipid composition as ER vesicles.

\section{Integrated approaches}

- New strategies to overcome biological barriers are based on multiple surface modifications that confer several functionalities on the carrier. The main strategies are based on polymers or particles that have buffering proprieties, and multistage systems that sequentially overcome various biological barriers. Another strategy is based on biomimetic approaches; the surface of nanocarriers can be modified with natural membrane coating, which improves their biocompatibility, self-tolerance and local increase in inflamed vasculature.

\section{References}

Papers of special note have been highlighted as

- of interest

1 Torchilin VP. Recent advances with liposomes as pharmaceutical carriers. Nat. Rev. Drug Discov. 4(2), 145-160 (2005).

- Describes many liposomal drugs, from clinically approved products to new experimental applications with gene delivery and cancer therapy.

2 Davis ME. Nanoparticle therapeutics: an emerging treatment modality for cancer. Nat. Rev. Drug Discov. 7(9), 771-782 (2008).
3 Lammers T, Hennink WE, Storm G. Tumour-targeted nanomedicines: principles and practice. Br. J. Cancer 99(3), 392-397 (2008).

4 Swami A, Shi J, Gadde S, Votruba AR, Kolishetti N, Farokhzad OC. Nanoparticles for targeted and temporally controlled drug delivery. In: Multifunctional Nanoparticles for Drug Delivery Applications. Springer, NY, USA, 9-29 (2012).

5 Wang J, Lu Z, Wientjes MG, Au JLS. Delivery of siRNA therapeutics: barriers and carriers. AAPS J. 12(4), 492-503 (2010).

6 Hoffman AS. Hydrogels for biomedical applications. Adv. Drug Deliv. Rev. 64, 18-23 (2012). 
$7 \quad$ Qiu Y, Park K. Environment-sensitive hydrogels for drug delivery. Adv. Drug Deliv. Rev. 64, 49-60 (2012).

8 Hoffman AS. Stimuli-responsive polymers: biomedical applications and challenges for clinical translation. Adv. Drug Deliv. Rev. 65(1), 10-16 (2013).

9 Petros RA, Desimone JM. Strategies in the design of nanoparticles for therapeutic applications. Nat. Rev. Drug Discov. 9(8), 615-627 (2010).

10 Gratton SE, Ropp PA, Pohlhaus PD et al. The effect of particle design on cellular internalization pathways. Proc. Natl Acad. Sci. 105(33), 11613-11618 (2008).

11 Albanese A, Tang PS, Chan WC. The effect of nanoparticle size, shape, and surface chemistry on biological systems. Ann. Rev. Biomed. Eng. 14, 1-16 (2012).

12 Varkouhi AK, Scholte M, Storm G, Haisma HJ. Endosomal escape pathways for delivery of biologicals. J. Control. Release 151(3), 220-228 (2011).

- Describes many different strategies to obtain the endosomal escape thereby enabling the cytosolic delivery of therapeutics.

13 Mellman I. Endocytosis and molecular sorting. Annu. Rev. Cell. Dev. Biol. 12, 575-625 (1996).

14 Lodish H, Berk A, Zipursky SL, Matsudaira P, Baltimore D, Darnell J. Molecular Cell Biology (4th Edition). W H Freeman, NY, USA (2000).

15 Molinaro R, Wolfram J, Federico C et al. Polyethylenimine and chitosan carriers for the delivery of RNA interference effectors. Expert Opin. Drug Deliv. 10(12), 1653-1668 (2013).

16 Madani F, Lindberg S, Langel Ü, Futaki S, Gräslund A. Mechanisms of cellular uptake of cell-penetrating peptides. J. Biophys. doi:10.1155/2011/414729 (2011) (Epub ahead of print).

17 Koren E, Torchilin VP. Cell-penetrating peptides: breaking through to the other side. Trends Mol. Med. 18(7), 385-393 (2012).

18 Sandgren S, Cheng F, Belting M. Nuclear targeting of macromolecular polyanions by an HIV-Tat derived peptide Role for cell-surface proteoglycans. J. Biol. Chem. 277(41), 38877-38883 (2002).

19 Console S, Marty C, García-Echeverría C, Schwendener R, Ballmer-Hofer K. Antennapedia and HIV transactivator of transcription (TAT) "protein transduction domains" promote endocytosis of high molecular weight cargo upon binding to cell surface glycosaminoglycans. J. Biol. Chem. 278(37), 35109-35114 (2003).

20 Lindgren M, Hällbrink M, Prochiantz A, Langel Ü. Cellpenetrating peptides. Trends Pharmacol. Sci. 21(3), 99-103 (2000).

21 Torchilin VP. Recent approaches to intracellular delivery of drugs and DNA and organelle targeting. Annu. Rev. Biomed. Eng. 8, 343-375 (2006).

22 Sakhrani NM, Padh H. Organelle targeting: third level of drug targeting. Drug Des. Devel. Ther. 7, 585-599 (2013).

23 Maniti O, Blanchard E, Trugnan G, Lamazière A, AyalaSanmartin J. Metabolic energy-independent mechanism of internalization for the cell penetrating peptide penetratin. Int. J. Biochem. Cell Biol. 44(6), 869-875 (2012).

24 Patel LN, Zaro JL, Shen W-C. Cell penetrating peptides: intracellular pathways and pharmaceutical perspectives. Pharmaceut. Res. 24(11), 1977-1992 (2007).

25 Kaplan IM, Wadia JS, Dowdy SF. Cationic TAT peptide transduction domain enters cells by macropinocytosis. J. Control. Release 102(1), 247-253 (2005).

26 Duchardt F, Fotin-Mleczek M, Schwarz H, Fischer R, Brock R. A comprehensive model for the cellular uptake of cationic cell-penetrating peptides. Traffic 8(7), 848-866 (2007).

27 Madani F, Lindberg S, Langel U, Futaki S, Graslund A. Mechanisms of cellular uptake of cell-penetrating peptides. J. Biophys. 2011, 414729

28 Maiolo JR, Ferrer M, Ottinger EA. Effects of cargo molecules on the cellular uptake of arginine-rich cellpenetrating peptides. Biochim. Biophys. Acta 1712(2), 161-172 (2005).

29 Yang X, Chen Q-Y, Li X, Gao J. Functional ionic liquids induced the formation of mitochondria targeted fluorescent core-shell ellipsoidal nanoparticles with anticancer properties. Colloids Surf. B. Biointerfaces 98, 91-96 (2012).

30 Krpetic ZE, Saleemi S, Prior IA, Sée V, Qureshi R, Brust M. Negotiation of intracellular membrane barriers by TATmodified gold nanoparticles. ACS Nano 5(6), 5195-5201 (2011).

- Contributes to the debate about how nano-sized objects negotiate membrane barriers inside biological cells. The transactivator of transcription (TAT) peptide is particularly effective in promoting cellular uptake.

31 Liu J, Zhao Y, Guo Q et al. TAT-modified nanosilver for combating multidrug-resistant cancer. Biomaterials 33(26), 6155-6161 (2012).

32 Tian X-H, Wei F, Wang T-X et al. Blood-brain barrier transport of Tat peptide and polyethylene glycol decorated gelatin-siloxane nanoparticle. Mater. Lett. 68, 94-96 (2012).

33 Qin Y, Chen HL, Yuan WM et al. Liposome formulated with TAT-modified cholesterol for enhancing the brain delivery. Int. J. Pharmaceut. 419(1-2), 85-95 (2011).

34 Laquintana V, Trapani A, Denora N, Wang F, Gallo JM, Trapani G. New strategies to deliver anticancer drugs to brain tumors. Expert Opin. Drug Deliv. 6(10), 1017-1032 (2009).

35 Jain A, Yadav BK, Chugh A. Marine antimicrobial peptide tachyplesin as an efficient nanocarrier for macromolecule delivery in plant and mammalian cells. FEBS J. 282(4), $732-745$ (2015).

36 Zasloff M. Magainins, a class of antimicrobial peptides from Xenopus skin: isolation, characterization of two active forms, and partial cDNA sequence of a precursor. Proc. Natl Acad. Sci. USA 84(15), 5449-5453 (1987).

37 Pushpanathan M, Gunasekaran P, Rajendhran J. Antimicrobial peptides: versatile biological properties. Int. J. Pept. doi:10.1155/2013/675391 (2013) (Epub ahead of print).

38 Vale N, Aguiar L, Gomes P. Antimicrobial peptides: a new class of antimalarial drugs? Front. Pharmacol. 5, 275 (2014). 
39 Scudiero O, Galdiero S, Cantisani M et al. Novel synthetic, salt-resistant analogs of human beta-defensins 1 and 3 endowed with enhanced antimicrobial activity. Antimicrob. Agents Chemother. 54(6), 2312-2322 (2010).

40 Scudiero O, Galdiero S, Nigro E et al. Chimeric betadefensin analogs, including the novel $3 \mathrm{NI}$ analog, display salt-resistant antimicrobial activity and lack toxicity in human epithelial cell lines. Antimicrob. Agents Chemother. 57(4), 1701-1708 (2013).

41 Colavita I, Nigro E, Sarnataro D et al. Membrane protein $4 \mathrm{~F} 2 / \mathrm{CD} 98$ is a cell surface receptor involved in the internalization and trafficking of human $\beta$-defensin 3 in epithelial cells. Chem. Biol. 22(2), 217-228 (2015).

42 Golubeva OY, Shamova O, Orlov D et al. Synthesis and study of antimicrobial activity of bioconjugates of silver nanoparticles and endogenous antibiotics. Glass Phys. Chem. 37(1), 78-84 (2011).

43 Yang K, Gitter B, Rüger R et al. Antimicrobial peptidemodified liposomes for bacteria targeted delivery of temoporfin in photodynamic antimicrobial chemotherapy. Photochem. Photobiol. Sci. 10(10), 1593-1601 (2011).

44 Pacor S, Giangaspero A, Bacac M, Sava G, Tossi A. Analysis of the cytotoxicity of synthetic antimicrobial peptides on mouse leucocytes: implications for systemic use. J. Antimicrob. Chemother. 50 (3), 339-348 (2002).

45 Hancock RE. Cationic peptides: effectors in innate immunity and novel antimicrobials. Lancet Infect. Dis. 1(3), 156-164 (2001).

46 Wang L, Liu Y, Li W et al. Selective targeting of gold nanorods at the mitochondria of cancer cells: implications for cancer therapy. Nano Lett. 11(2), 772-780 (2010).

47 Pfeifer A, Verma IM. Gene therapy: Promises and problems. Annu. Rev. Gen. Hum. Genet. 2, 177-211 (2001).

48 Kay MA, Glorioso JC, Naldini L. Viral vectors for gene therapy: the art of turning infectious agents into vehicles of therapeutics. Nat. Med. 7(1), 33-40 (2001).

49 Benjaminsen RV, Mattebjerg MA, Henriksen JR, Moghimi SM, Andresen TL. The possible "proton sponge" effect of polyethylenimine (PEI) does not include change in lysosomal pH. Mol. Ther. 21(1), 149-157 (2013).

50 Nel AE, Madler L, Velegol D et al. Understanding biophysicochemical interactions at the nano-bio interface. Nat. Mat. 8(7), 543-557 (2009).

51 Godbey WT, Wu KK, Mikos AG. Poly(ethylenimine)mediated gene delivery affects endothelial cell function and viability. Biomaterials 22(5), 471-480 (2001).

52 Xia TA, Kovochich M, Liong M et al. Polyethyleneimine coating enhances the cellular uptake of mesoporous silica nanoparticles and allows safe delivery of siRNA and DNA constructs. ACS Nano 3(10), 3273-3286 (2009).

53 Dufes C, Uchegbu IF, Schatzlein AG. Dendrimers in gene delivery. Adv. Drug Deliv. Rev. 57(15), 2177-2202 (2005).

54 Radu DR, Lai CY, Jeftinija K, Rowe EW, Jeftinija $S$, Lin VSY. A polyamidoamine dendrimer-capped mesoporous silica nanosphere-based gene transfection reagent. J. Am. Chem. Soc. 126(41), 13216-13217 (2004).
55 Vicent MJ, Dieudonne L, Carbajo RJ, Pineda-Lucena A. Polymer conjugates as therapeutics: future trends, challenges and opportunities. Expert Opin. Drug Deliv. 5(5), 593-614 (2008).

56 Sun JT, Hong CY, Pan CY. Fabrication of PDEAEMA-coated mesoporous silica nanoparticles and $\mathrm{pH}$-responsive controlled release. J. Phys. Chem. C. 114(29), 12481-12486 (2010).

57 Marek SR, Conn CA, Peppas NA. Cationic nanogels based on diethylaminoethyl methacrylate. Polymer 51(6), 1237-1243 (2010).

58 You YZ, Manickam DS, Zhou QH, Oupicky D. Reducible poly(2-dimethylaminoethyl methaerylate): synthesis, cytotoxicity, and gene delivery activity. J. Control. Release 122(3), 217-225 (2007).

59 Gao Q, Xu Y, Wu D, Sun YH, Li XA. pH-Responsive drug release from polymer-coated mesoporous silica spheres. J. Phys. Chem. C 113(29), 12753-12758 (2009).

60 Midoux P, Pichon C, Yaouanc JJ, Jaffrã “S PA. Chemical vectors for gene delivery: a current review on polymers, peptides and lipids containing histidine or imidazole as nucleic acids carriers. Br. J. Pharm. 157(2), 166-178 (2009).

61 Liang W, Lam JK. Endosomal escape pathways for nonviral nucleic acid delivery systems. (2012). www.intechopen.com/books

62 Wu H, Zhu L, Torchilin VP. pH-sensitive poly(histidine)PEG/DSPE-PEG co-polymer micelles for cytosolic drug delivery. Biomaterials 34(4), 1213-1222 (2013).

63 Gillard M, Jia ZF, Jia J et al. Intracellular trafficking pathways for nuclear delivery of plasmid DNA complexed with highly efficient endosome escape polymers. Biomacromolecules 15(10), 3569-3576 (2014).

64 Hong SP, Leroueil PR, Janus EK et al. Interaction of polycationic polymers with supported lipid bilayers and cells: nanoscale hole formation and enhanced membrane permeability. Bioconjug. Chem. 17(3), 728-734 (2006).

65 Convertine AJ, Diab C, Prieve M et al. $\mathrm{pH}$-responsive polymeric micelle carriers for siRNA drugs. Biomacromolecules 11(11), 2904-2911 (2010).

66 Lackey CA, Press OW, Hoffman AS, Stayton PS. A biomimetic $\mathrm{pH}$-responsive polymer directs endosomal release and intracellular delivery of an endocytosed antibody complex. Bioconjug. Chem. 13(5), 996-1001 (2002).

67 El-Sayed MEH, Hoffman AS, Stayton PS. Rational design of composition and activity correlations for $\mathrm{pH}$-sensitive and glutathione-reactive polymer therapeutics. J. Control. Release 101(1-3), 47-58 (2005).

68 Meier O, Greber UF. Adenovirus endocytosis. J. Gene Med. 6, S152-S163 (2004).

69 Hogle JM. Poliovirus cell entry: common structural themes in viral cell entry pathways. Annu. Rev. Microbiol. 56, 677-702 (2002).

70 Mandal M, Lee KD. Listeriolysin O-liposome-mediated cytosolic delivery of macromolecule antigen in vivo: enhancement of antigen-specific cytotoxic T lymphocyte frequency, activity, and tumor protection. Biochim. Biophys. Acta Biomembranes 1563(1-2), 7-17 (2002). 
71 Parente RA, Nir S, Szoka FC. pH-dependent fusion of phosphatidylcholine small vesicles - induction by a synthetic amphipathic peptide. J. Biol. Chem. 263(10), 4724-4730 (1988).

72 Kullberg M, Owens JL, Mann K. Listeriolysin O enhances cytoplasmic delivery by Her-2 targeting liposomes. J. Drug Target. 18(4), 313-320 (2010).

73 Ogris M, Carlisle RC, Bettinger T, Seymour LW. Melittin enables efficient vesicular escape and enhanced nuclear access of nonviral gene delivery vectors. J. Biol. Chem. 276(50), 47550-47555 (2001).

74 Dempsey CE. The actions of melittin on membranes. Biochim. Biophys. Acta 1031(2), 143-161 (1990).

75 Boeckle S, Fahrmeir J, Roedl W, Ogris M, Wagner E. Melittin analogs with high lytic activity at endosomal $\mathrm{pH}$ enhance transfection with purified targeted PEI polyplexes. J. Control. Release 112(2), 240-248 (2006).

76 Kakimoto S, Hamada T, Komatsu Y et al. The conjugation of diphtheria toxin $\mathrm{T}$ domain to poly(ethylenimine) based vectors for enhanced endosomal escape during gene transfection. Biomaterials 30 (3), 402-408 (2009).

77 Oliveira S, Van Rooy I, Kranenburg O, Storm G, Schiffelers RM. Fusogenic peptides enhance endosomal escape improving siRNA-induced silencing of oncogenes. Int. J. Pharmaceut. 331(2), 211-214 (2007).

78 Mastrobattista E, Koning GA, Van Bloois L, Filipe ACS, Jiskoot W, Storm G. Functional characterization of an endosome-disruptive peptide and its application in cytosolic delivery of immunoliposome-entrapped proteins. J. Biol. Chem. 277(30), 27135-27143 (2002).

79 Funhoff AM, Van Nostrum CF, Janssen APCA, Fens MHaM, Crommelin DJA, Hennink WE. Polymer sidechain degradation as a tool to control the destabilization of polyplexes. Pharmaceut. Res. 21(1), 170-176 (2004).

80 Funhoff AM, Van Nostrum CF, Lok MC, Fretz MM, Crommelin DJA, Hennink WE. Poly(3-guanidinopropyl methacrylate): a novel cationic polymer for gene delivery. Bioconjug. Chem. 15(6), 1212-1220 (2004).

81 Jiang X, Lok MC, Hennink WE. Degradable-brushed pHEMA-pDMAEMA synthesized via ATRP and click chemistry for gene delivery. Bioconjug. Chem. 18(6), 2077-2084 (2007).

82 Min SH, Lee DC, Lim MJ et al. A composite gene delivery system consisting of polyethylenimine and an amphipathic peptide KALA. J. Gene Med. 8(12), 1425-1434 (2006).

83 Futaki S, Masui Y, Nakase I et al. Unique features of a $\mathrm{pH}$ sensitive fusogenic peptide that improves the transfection efficiency of cationic liposomes. J. Gene Med. 7(11), 1450-1458 (2005).

84 Sasaki K, Kogure K, Chaki S et al. An artificial virus-like nano carrier system: enhanced endosomal escape of nanoparticles via synergistic action of $\mathrm{pH}$-sensitive fusogenic peptide derivatives. Anal. Bioanal. Chem. 391(8), 2717-2727 (2008).

85 Kakudo T, Chaki S, Futaki $S$ et al. Transferrin-modified liposomes equipped with a $\mathrm{pH}$-sensitive fusogenic peptide: an artificial viral-like delivery system. Biochemistry 43(19), 5618-5628 (2004).
86 Ulrich AS. Biophysical aspects of using liposomes as delivery vehicles. Biosci. Rep. 22(2), 129-150 (2002).

87 Mo R, Sun Q, Li N, Zhang C. Intracellular delivery and antitumor effects of $\mathrm{pH}$-sensitive liposomes based on zwitterionic oligopeptide lipids. Biomaterials 34(11), 2773-2786 (2013).

88 Liu Q, Jiang QQ, Yi WJ et al. Novel imidazolefunctionalized cyclen cationic lipids: synthesis and application as non-viral gene vectors. Bioorg. Med. Chem. 21(11), 3105-3113 (2013).

89 Billiet L, Gomez JP, Berchel M et al. Gene transfer by chemical vectors, and endocytosis routes of polyplexes, lipoplexes and lipopolyplexes in a myoblast cell line. Biomaterials 33(10), 2980-2990 (2012).

90 Gonçalves C, Berchel M, Gosselin M-P et al. Lipopolyplexes comprising imidazole/imidazolium lipophosphoramidate, histidinylated polyethyleneimine and siRNA as efficient formulation for siRNA transfection. Int. J. Pharmaceut. 460(1), 264-272 (2013).

91 Cooper GM, Hausman RE. The Cell. ASM Press, Washington, USA (2000).

92 Görlich D, Kutay U. Transport between the cell nucleus and the cytoplasm. Annu. Rev. Cell Devel. Biol. 15(1), 607-660 (1999).

93 Parks SB, Kushner JD, Nauman D et al. Lamin A/C mutation analysis in a cohort of 324 unrelated patients with idiopathic or familial dilated cardiomyopathy. Am. Heart J. 156(1), 161-169 (2008).

94 Muchir A, Bonne G, Van Der Kooi AJ et al. Identification of mutations in the gene encoding lamins $\mathrm{A} / \mathrm{C}$ in autosomal dominant limb girdle muscular dystrophy with atrioventricular conduction disturbances (LGMD1B). Hum. Mol. Genet. 9(9), 1453-1459 (2000).

95 Peters MF, Nucifora Jr FC, Kushi J et al. Nuclear targeting of mutant Huntingtin increases toxicity. Mol. Cell. Neurosci. 14(2), 121-128 (1999).

96 Zhang LW, Monteiro-Riviere NA. Mechanisms of quantum dot nanoparticle cellular uptake. Toxicol. Sci. 110(1), 138-155 (2009).

97 Panyam J, Labhasetwar V. Biodegradable nanoparticles for drug and gene delivery to cells and tissue. Adv. Drug Deliv. Rev. 55(3), 329-347 (2012).

98 Asati A, Santra S, Kaittanis C, Perez JM. Surface-chargedependent cell localization and cytotoxicity of cerium oxide nanoparticles. ACS Nano 4(9), 5321-5331 (2010).

99 Tkachenko AG, Xie H, Coleman D et al. Multifunctional gold nanoparticle-peptide complexes for nuclear targeting. J. Am. Chem. Soc. 125(16), 4700-4701 (2003).

100 Suntharalingam M, Wente SR. Peering through the pore: nuclear pore complex structure, assembly, and function. Dev. Cell 4(6), 775-789 (2003).

101 Cook A, Bono F, Jinek M, Conti E. Structural biology of nucleocytoplasmic transport. Annu. Rev. Biochem. 76, 647-671 (2007).

102 Kubitscheck U, Grünwald D, Hoekstra A et al. Nuclear transport of single molecules dwell times at the nuclear pore complex. J. Cell Biol. 168(2), 233-243 (2005). 
103 Raoof M, Mackeyev Y, Cheney MA, Wilson LJ, Curley SA. Internalization of C60 fullerenes into cancer cells with accumulation in the nucleus via the nuclear pore complex. Biomaterials 33(10), 2952-2960 (2012).

104 Biswas S, Dodwadkar NS, Deshpande PP, Torchilin VP. Liposomes loaded with paclitaxel and modified with novel triphenylphosphonium-PEG-PE conjugate possess low toxicity, target mitochondria and demonstrate enhanced antitumor effects in vitro and in vivo. J. Control Release 159(3), 393-402 (2012).

105 Liu J-N, Bu W, Pan L-M et al. Simultaneous nuclear imaging and intranuclear drug delivery by nuclear-targeted multifunctional upconversion nanoprobes. Biomaterials 33(29), $7282-7290$ (2012).

106 Pan L, He Q, Liu J et al. Nuclear-targeted drug delivery of TAT peptide-conjugated monodisperse mesoporous silica nanoparticles. J. Am. Chem. Soc. 134(13), 5722-5725 (2012).

107 Masuda T, Akita H, Nishio T et al. Development of lipid particles targeted via sugar-lipid conjugates as novel nuclear gene delivery system. Biomaterials 29(6), 709-723 (2008).

108 Niikura K, Sekiguchi S, Nishio T et al. Oligosaccharidemediated nuclear transport of nanoparticles. ChemBioChem. 9(16), 2623-2627 (2008).

109 Eguchi A, Furusawa H, Yamamoto A et al. Optimization of nuclear localization signal for nuclear transport of DNAencapsulating particles. J. Control. Release 104(3), 507-519 (2005).

110 Porkka K, Laakkonen P, Hoffman JA, Bernasconi M, Ruoslahti E. A fragment of the HMGN2 protein homes to the nuclei of tumor cells and tumor endothelial cells in vivo. Proc. Natl Acad. Sci. 99(11), 7444-7449 (2002).

111 Kang B, Mackey MA, El-Sayed MA. Nuclear targeting of gold nanoparticles in cancer cells induces DNA damage, causing cytokinesis arrest and apoptosis. J. Am. Chem. Soc. 132(5), 1517-1519 (2010).

112 Mackey MA, Saira F, Mahmoud MA, El-Sayed MA. Inducing cancer cell death by targeting its nucleus: solid gold nanospheres versus hollow gold nanocages. Bioconjug. Chem. 24(8), 897-906 (2013).

113 Ziegler A, Seelig J. High affinity of the cell-penetrating peptide HIV-1 Tat-PTD for DNA. Biochemistry 46(27), 8138-8145 (2007)

114 Pan L, Liu J, He Q, Wang L, Shi J. Overcoming multidrug resistance of cancer cells by direct intranuclear drug delivery using TAT-conjugated mesoporous silica nanoparticles. Biomaterials 34(11), 2719-2730 (2013).

- The authors demonstrate the effective circumvention of multidrug resistance in cancer cells by an active nucleartargeted drug delivery system, which was constructed by conjugating TAT peptide onto the surface of mesoporous silica nanoparticles.

115 Misra R, Sahoo SK. Intracellular trafficking of nuclear localization signal conjugated nanoparticles for cancer therapy. Eur. J. Pharmaceut. Sci. 39(1), 152-163 (2010).

116 Jana A, Saha B, Banerjee DR et al. Photocontrolled nucleartargeted drug delivery by single component photoresponsive fluorescent organic nanoparticles of acridin-9-methanol. Bioconjug. Chem. 24(11), 1828-1839 (2013).

117 Grandinetti G, Reineke TM. Exploring the mechanism of plasmid DNA nuclear internalization with polymer-based vehicles. Mol. Pharmaceut. 9(8), 2256-2267 (2012).

118 Grandinetti G, Smith AE, Reineke TM. Membrane and nuclear permeabilization by polymeric $\mathrm{pDNA}$ vehicles: efficient method for gene delivery or mechanism of cytotoxicity? Mol. Pharmaceut. 9(3), 523-538 (2012).

119 Yuan Y, Chen S, Paunesku T et al. Epidermal growth factor receptor targeted nuclear delivery and high-resolution whole cell X-ray imaging of $\mathrm{Fe} 3 \mathrm{O} 4 @ \mathrm{TiO} 2$ nanoparticles in cancer cells. ACS Nano 7(12), 10502-10517 (2013).

120 Lodish H, Berk A, Zipursky SL, Matsudaira P, Baltimore D, Darnell J. Integrating cells into tissues. In: Molecular Cell Biology (4th Edition). W. H. Freeman and Company NY, USA (2000).

121 Davidson SM, Duchen MR. Effects of NO on mitochondrial function in cardiomyocytes: pathophysiological relevance. Cardiovasc. Res. 71(1), 10-21 (2006).

122 Dias N, Bailly C. Drugs targeting mitochondrial functions to control tumor cell growth. Biochem. Pharmacol. 70(1), $1-12(2005)$.

123 Kwong JQ, Beal MF, Manfredi G. The role of mitochondria in inherited neurodegenerative diseases. J. Neurochem. 97(6), 1659-1675 (2006).

124 Liu J, Ames BN. Reducing mitochondrial decay with mitochondrial nutrients to delay and treat cognitive dysfunction, Alzheimer's disease, and Parkinson's disease. Nutr. Neurosci. 8(2), 67-89 (2005).

125 Wiederkehr A, Wollheim CB. Minireview: implication of mitochondria in insulin secretion and action. Endocrinology 147(6), 2643-2649 (2006).

126 Riganti C, Rolando B, Kopecka J et al. Mitochondrialtargeting nitrooxy-doxorubicin: a new approach to overcome drug resistance. Mol. Pharm. 10(1), 161-174 (2012).

127 Han M, Vakili MR, Soleymani Abyaneh H, Molavi O, Lai R, Lavasanifar A. Mitochondrial delivery of doxorubicin via triphenylphosphine modification for overcoming drug resistance in MDA-MB-435/DOX cells. Mol. Pharm. 11(8), 2640-2649 (2014).

128 Zhao K, Zhao G-M, Wu D et al. Cell-permeable peptide antioxidants targeted to inner mitochondrial membrane inhibit mitochondrial swelling, oxidative cell death, and reperfusion injury. J. Biol. Chem. 279(33), 34682-34690 (2004).

129 Yoong SL, Wong BS, Zhou QL et al. Enhanced cytotoxicity to cancer cells by mitochondria-targeting MWCNTs containing platinum (IV) prodrug of cisplatin. Biomaterials 35(2), 748-759 (2014)

130 Murphy MP. Targeting lipophilic cations to mitochondria. Biochim. Biophys. Acta (BBA)-Bioenergetics 1777(7), 1028-1031 (2008)

131 Marrache S, Dhar S. Engineering of blended nanoparticle platform for delivery of mitochondria-acting therapeutics. Proc. Natl Acad. Sci. 109(40), 16288-16293 (2012).

- The authors report a rationally designed mitochondriatargeted polymeric nanoparticle system and its 
optimization for efficient delivery of various mitochondriaacting therapeutics.

132 Hoshino A, Fujioka K, Oku T et al. Quantum dots targeted to the assigned organelle in living cells. Microbiol. Immunol. 48(12), 985-994 (2004).

133 Weissig V, Lasch J, Erdos G, Meyer HW, Rowe TC, Hughes J. DQAsomes: a novel potential drug and gene delivery system made from dequalinium ${ }^{\mathrm{TM}}$. Pharmaceut. Res. 15(2), 334-337 (1998).

134 D'souza GG, Boddapati SV, Weissig V. Mitochondrial leader sequence-plasmid DNA conjugates delivered into mammalian cells by DQAsomes co-localize with mitochondria. Mitochondrion 5(5), 352-358 (2005).

135 Weiss MJ, Wong JR, Ha CS et al. Dequalinium, a topical antimicrobial agent, displays anticarcinoma activity based on selective mitochondrial accumulation. Proc. Natl Acad. Sci. 84(15), 5444-5448 (1987).

136 Wang X-X, Li Y-B, Yao H-J et al. The use of mitochondrial targeting resveratrol liposomes modified with a dequalinium polyethylene glycol-distearoylphosphatidyl ethanolamine conjugate to induce apoptosis in resistant lung cancer cells. Biomaterials 32(24), 5673-5687 (2011).

137 Yamada Y, Akita H, Kamiya H et al. MITO-Porter: a liposome-based carrier system for delivery of macromolecules into mitochondria via membrane fusion. Biochim. Biophys. Acta (BBA)-Biomembranes 1778(2), 423-432 (2008).

138 Yasuzaki Y, Yamada Y, Harashima H. Mitochondrial matrix delivery using MITO-Porter, a liposome-based carrier that specifies fusion with mitochondrial membranes. Biochem. Biophys. Res. Commun. 397(2), 181-186 (2010).

139 Yamada Y, Furukawa R, Yasuzaki Y, Harashima H. Dual function MITO-Porter, a nano carrier integrating both efficient cytoplasmic delivery and mitochondrial macromolecule delivery. Mol. Ther. 19(8), 1449-1456 (2011).

140 Agemy L, Friedmann-Morvinski D, Kotamraju VR et al. Targeted nanoparticle enhanced proapoptotic peptide as potential therapy for glioblastoma. Proc. Natl Acad. Sci. 108(42), 17450-17455 (2011).

141 Kim D, Lee ES, Oh KT, Gao ZG, Bae YH. Doxorubicinloaded polymeric micelle overcomes multidrug resistance of cancer by double-targeting folate receptor and early endosomal pH. Small 4(11), 2043-2050 (2008).

142 Midoux P, Pichon C, Yaouanc JJ, Jaffrès PA. Chemical vectors for gene delivery: a current review on polymers, peptides and lipids containing histidine or imidazole as nucleic acids carriers. Br. J. Pharm. 157(2), 166-178 (2009).

143 Wen Y, Guo Z, Du Z et al. Serum tolerance and endosomal escape capacity of histidine-modified pDNA-loaded complexes based on polyamidoamine dendrimer derivatives. Biomaterials 33(32), 8111-8121 (2012).

144 Lee ES, Na K, Bae YH. Super pH-sensitive multifunctional polymeric micelle. Nano lett. 5(2), 325-329 (2005).

145 Kim I, Xu WJ, Reed JC. Cell death and endoplasmic reticulum stress: disease relevance and therapeutic opportunities. Nat. Rev. Drug Discov. 7(12), 1013-1030 (2008).
146 Ma YJ, Hendershot LM. ER chaperone functions during normal and stress conditions. J. Chem. Neuroanat. 28(1-2), 51-65 (2004).

147 Xu CY, Bailly-Maitre B, Reed JC. Endoplasmic reticulum stress: cell life and death decisions. J. Clin. Invest. 115(10), 2656-2664 (2005).

148 Neve EPA, Ingelman-Sundberg M. Cytochrome P450 proteins: retention and distribution from the endoplasmic reticulum. Curr. Opin. Drug Discov. Devel. 13(1), 78-85 (2010).

149 Unterberger U, Hoftberger R, Gelpi E, Flicker H, Budka $\mathrm{H}$, Voigtlander T. Endoplasmic reticulum stress features are prominent in Alzheimer disease but not in prion diseases in vivo. J. Neuropathol. Exp. Neurol. 65(4), 348-357 (2006).

150 Bi MX, Naczki C, Koritzinsky M et al. ER stress-regulated translation increases tolerance to extreme hypoxia and promotes tumor growth. EMBO J. 24(19), 3470-3481 (2005).

151 Ozcan U, Cao Q, Yilmaz E et al. Endoplasmic reticulum stress links obesity, insulin action, and type 2 diabetes. Science 306(5695), 457-461 (2004).

152 Glembotski CC. The role of the unfolded protein response in the heart. J. Mol. Cell. Cardiol. 44(3), 453-459 (2008).

153 Capitani M, Sallese M. The KDEL receptor: new functions for an old protein. Febs Lett. 583(23), 3863-3871 (2009).

154 Acharya S, Hill RA. High efficacy gold-KDEL peptidesiRNA nanoconstruct-mediated transfection in $\mathrm{C} 2 \mathrm{C} 12$ myoblasts and myotubes. Nanomedicine 10(2), 329-337 (2014).

- The authors demonstrate that a delivery system composed of gold nanoparticle and KDEL-based siRNA is superior to lipofectamine in delivering siRNA in differentiated myoblasts.

155 Delie F, Petignat P, Cohen M. GRP78-targeted nanotherapy against castrate-resistant prostate cancer cells expressing membrane GRP78. Target Oncol. 8(4), 225-230

156 Rajendran L, Knolker HJ, Simons K. Subcellular targeting strategies for drug design and delivery. Nat. Rev. Drug Discov. 9(1), 29-42 (2010).

157 Leifert JA, Rodriguez-Carreno MP, Rodriguez F, Whitton JL. Targeting plasmid-encoded proteins to the antigen presentation pathways. Immunol. Rev. 199(1), 40-53 (2004).

158 Hayashi A, Wakita H, Yoshikawa T et al. A strategy for efficient cross-presentation of CTL-epitope peptides leading to enhanced induction of in vivo tumor immunity. J. Control. Release 117(1), 11-19 (2007).

159 Swift LL. Assembly of very-low-density lipoproteins in ratliver - a study of nascent particles recovered from the rough endoplasmic-reticulum. J. Lipid Res. 36(3), 395-406 (1995).

160 Pollock S, Antrobus R, Newton L et al. Uptake and trafficking of liposomes to the endoplasmic reticulum. FASEB J. 24(6), 1866-1878 (2010).

161 Greish K. Enhanced permeability and retention (EPR) effect for anticancer nanomedicine drug targeting. In: Cancer Nanotechnology. Springer, NY, USA, 25-37 (2010).

162 Modi S, Prakash Jain J, Domb A, Kumar N. Exploiting EPR in polymer drug conjugate delivery for tumor targeting. Curr. Pharm. Des. 12(36), 4785-4796 (2006). 
163 Roberts M, Bentley M, Harris J. Chemistry for peptide and protein PEGylation. Adv. Drug Deliv. Rev. 54(4), 459-476 (2002).

164 Sacchetti C, Motamedchaboki K, Magrini A et al. Surface polyethylene glycol conformation influences the protein corona of polyethylene glycol-modified single-walled carbon nanotubes: potential implications on biological performance. ACS Nano 7(3), 1974-1989 (2013).

165 Yamada K, Yoshii S, Kumagai S et al. High-density and highly surface selective adsorption of protein-nanoparticle complexes by controlling electrostatic interaction. Jpn J. Appl. Phys. 45(5R), 4259 (2006).

166 Cheng Z, Al Zaki A, Hui JZ, Muzykantov VR, Tsourkas A. Multifunctional nanoparticles: cost versus benefit of adding targeting and imaging capabilities. Science 338(6109), 903-910 (2012).

167 Tasciotti E, Liu X, Bhavane R et al. Mesoporous silicon particles as a multistage delivery system for imaging and therapeutic applications. Nat. Nanotechnol. 3(3), 151-157 (2008).

168 Shen H, Sun T, Ferrari M. Nanovector delivery of siRNA for cancer therapy. Cancer Gene Ther. 19(6), 367-373 (2012).

169 Blanco E, Ferrari M. Emerging nanotherapeutic strategies in breast cancer. Breast 23(1), 10-18 (2014).

170 Torchilin V. Intracellular delivery of protein and peptide therapeutics. Drug Discov. Today Technol. 5(2), e95-e103 (2008).

171 Parodi A, Quattrocchi N, Van De Ven AL et al. Synthetic nanoparticles functionalized with biomimetic leukocyte membranes possess cell-like functions. Nat. Nanotechnol. 8(1), 61-68 (2013).
- The authors show that nanoporous silicon particles can successfully evade the immune system, cross the biological barriers of the body and localize at target tissues when they are coated with cellular membranes purified from leukocytes.

172 Corbo C, Parodi A, Evangelopoulos M et al. Proteomic profiling of a biomimetic drug delivery platform. Curr. Drug Targets (2014) (Epub ahead of print).

173 Parodi A, Quattrocchi N, Van De Ven AL et al. Synthetic nanoparticles functionalized with biomimetic leukocyte membranes possess cell-like functions. Nat. Nanotechnol. 8(1), 61-68 (2013).

174 Parodi A, Haddix SG, Taghipour N et al. Bromelain surface modification increases the diffusion of silica nanopartides in the tumor extracellular matrix. ACS Nano 8(10), 9874-9883 (2014).

175 Albini A, Mussi V, Parodi A et al. Interactions of single-wall carbon nanotubes with endothelial cells. Nanomedicine 6(2), 277-288 (2010).

176 Akita H, Kudo A, Minoura A et al. Multi-layered nanoparticles for penetrating the endosome and nuclear membrane via a step-wise membrane fusion process. Biomaterials 30 (15), 2940-2949 (2009).

177 Hatakeyama H, Akita H, Harashima H. A multifunctional envelope type nano device (MEND) for gene delivery to tumours based on the EPR effect: a strategy for overcoming the PEG dilemma. Adv. Drug Deliv. Rev. 63(3), 152-160 (2011).

178 Shaheen SM, Akita H, Nakamura T et al. KALA-modified multi-layered nanoparticles as gene carriers for MHC class-I mediated antigen presentation for a DNA vaccine. Biomaterials 32(26), 6342-6350 (2011). 